ISSN: 1978 - 8282

\title{
SISTEM UJIAN ONLINE CALON MAHASISWA BARU BERBASIS ILEARNING EDUCATION MARKETING PADA PERGURUAN TINGGI
}

\author{
Meta Amalya Dewi ${ }^{1}$ \\ Dede Cahyadi $^{2}$ \\ Yunita Wulansari ${ }^{3}$ \\ e-mail :meta@raharja.info; dede.cahyadi@raharja.info; yunita@raharja.info
}

Diterima : 02 Juli 2014 / Disetujui: 21 Juli 2014

\begin{abstract}
The development of increasingly advanced technology in support of services that can be accessed in various ways in an easy, fast efficient, anytime and anywhere. Services that were once only done face to face (face to face) started to turn into a more modern and sophisticated as electronic services which can be done relatively efficiently, effectively and quality. Therefore making an application service system that is precise and accurate support is needed for the marketing department to provide good service to prospective new students . With a line -based method, system service entrance exam (USM) Prospective New Student ( CMB ) will be very easy to do anywhere and not have to come to campus. The iRangers is a support system in the implementation of the entrance exam Prospective New Student online. Where highly supportive of service in Higher Education Campus Raharja be Featured in IT. In this article is described on issues that arise as well as solving the problem under study. In addition there are distinctive features and advantages of this application. In the implementation shown prtotoype view of application iRangers. It can be concluded that the contribution iRangers system can maximize marketing activities in serving new students to conduct online entrance examination. So the results of research more focused and interesting, and can be used as media and information services that are good for the entire private candidates raharja and society in general .
\end{abstract}

Keyword : iRangers, online, entrance exam.

1. Dosen Jurusan Sistem Informasi, STMIK Raharja

Jl. Jend Sudirman No. 40 Modern Cikokol-Tangerang Telp. 5529692

2. Dosen Jurusan Komputerisasi Akuntansi, STMIK Raharja

Jl. Jend Sudirman No. 40 Modern Cikokol-Tangerang Telp. 5529692

3. Mahasiswa Jurusan Teknik Informasi, STMIK Raharja

Jl. Jend Sudirman No. 40 Modern Cikokol-Tangerang Telp. 5529692 


\begin{abstract}
ABSTRAKSI
Perkembangan Teknologi yang semakin maju dalam mendukung pelayanan yang dapat diakses dengan berbagai cara secara mudah , cepat efisien, kapan pun dan dimana pun. Pelayanan yang dulunya hanya dilakukan secara tatap muka ( face to face ) mulai berubah menjadi lebih modern dan canggih karena pelayanan secara elektronik yang relatif dapat dilakukan secara efisien, efektif dan berkualitas. Oleh karena itu pembuatan sebuah aplikasi sistem pelayanan dukungan yang tepat dan akurat sangat dibutuhkan untuk bagian marketing untuk nmemberikan pelayanan yang baik kepada calon mahasiswa baru. Dengan metode berbasis online, sistem pelayanan Ujian Seleksi Masuk (USM) Calon Mahasiswa Baru (CMB) akan sangat mudah dilakukan dimana saja dan tidak harus datang kekampus. Adapun iLearning Education Marketing merupakan sebuah sistem pendukung dalam pelaksanaan Ujian Seleksi Masuk Calon Mahasiswa Baru secara online. Dimana sangat mendukung pelayanan di Perguruan Tinggi Raharja menjadi Kampus Unggulan dibidang IT.Dalam Artikel ini dijelaskan mengenai masalah-masalah yang timbul serta pemecahan masalah yang diteliti. Selain itu terdapat ciri khas dan keunggulan dari aplikasi ini. Pada implementasinya ditampilkan tampilan prtotoype dari aplikasi iLearning Education Marketing. Maka dapat disimpulkan bahwa kontribusi sistem iLearning Education Marketing dapat memaksimalkan kegiatan dalam melayani calon mahsasiswa baru untuk melakukan ujian seleksi masuk secara online. Sehingga hasil penelitian lebih terarah dan menarik, serta dapat dijadikan media pelayanan dan informasi yang baik bagi seluruh calon pribadi raharja dan masyarakat secara umum.
\end{abstract}

Kata Kunci : iRangers, online,Ujian Saringan Masuk

\title{
PENDAHULUAN
}

Perkembangan Teknologi di saat ini sudah berkembang sangat pesat dan canggih, dari waktu ke waktu teknologi mengalami perubahan yang sangat besar. Teknologi saat ini berkembang dengan cepat, sehingga memacu konsep pelayanan yang semakin berkembang dan belakangan ini adalah pelayanan berbasis teknologi internet yaitu online yang sedikit meninggalkan berbasis tatap muka atau datang langsung ke tempat. Hal-hal itu menuntut bagian marketing harus berpikir bagaimana pelayanan yang diberikan sangat baik dan memuaskan yang mampu bersaing dalam dunia internasional.

Dengan adanya teknologi informasi akan mempermudah dalam memperoleh informasi yang efektif dan efisien. Untuk itu diperlukan suatu wujud teknologi informasi berupa sistem informasi yang dapat menunjang kinerja suatu instansi. Pemakaian sistem informasi sebagai alat pengolah data termasuk dalam kategori yang terbaik 
untuk saat ini, karena dapat meningkatkan kecepatan pekerjaan sehingga dicapai efisiensi tenaga dan waktu dalam mengolah data dibandingkan menggunakan metode secara manual. Karena dari kemajuan teknologi informasi itu tidak lepas dari peran dan pemanfaatan komputer serta internet, maka membuat sebuah pemikirian akan pemanfaatannya tersebut digunakan dalam sebuah pelayanan yang diberikan oleh sebuah instansi.

Mengapa hal tersebut bisa digunakan dalam sebuah pelayanan, karena dilihat dari kejadian-kejadian yang ada banyak pelayanan yang masih berjalan manual sehingga membuat pelayanan yang di berikan kurang optimal dan memuaskan para pelanggan. Dimana data yang ada masih dicatat dan pekerjaan yang dikerjakan petugas terlihat banyak.

Dalam memasuki dunia pendidikan khususnya di perguruan tinggi, calon mahasiswa baru di evaluasi terlebih dahulu dengan cara mengikuti ujian saringan masuk untuk mengukur taraf pencapaian siswa selama di sekolah menengah atas sebagai peserta didik, sehingga siswa/i dapat mengetahui kemampuannya dalam memahami bidang studi yang sudah ditempuh.Bila ternyata hasilnya kurang memuaskan atau belum maksimal, maka proses belajar harus ditingkatkan baik kualitas maupun kuantitas.

Dan ujian saringan masuk wajib di ikuti oleh seluruh calon mahasiswa baru di Perguruan Tinggi Raharja untuk melihat kemampuan dari calon pribadi raharja yang layak untuk menjadi Mahasiswa/i yang unggul nantinya dalam dunia pendidikan.

Oleh karena itu, iRangers merupakan sebuah sistem pendukung pelayanan bagian marketing dalam melayani calon mahasiswa baru untuk melakukan ujian saringan masuk secara online, dimana dengan ini turut membantu dalam pembelajaran iLearning agar nantinya calon mahasiswa baru dapat memahami dan mengerti dalam pembelajaran tersebut,

Saat ini Perguruan Tinggi Raharja adalah salah satu Perguruan Tinggi yang bergerak dibidang Ilmu Teknologi Komputer. Dengan adanya perkembangan Ilmu Teknologi itulah Perguruan Tinggi Rahraja ikut mengembangkan ilmu-ilmu yang disampaikan atau diberikan kepada mahasiswa/i guna untuk menciptakan lulusan yang berahklak mulia dan unggul dalam bidang ilmu teknologi komputer, karena menyesuaikan dengan kemajuan Ilmu teknologi itulah Perguruan Tinggi Raharja telah 
menciptakan dan menerapkan teknologi baru yaitu iLearning dalam proses kegiatan yang ada dikampus dan pembelajaran bagi seluruh Pribadi Raharja.

Dengan teknologi iLearning tersebut, proses pembelajaran di Perguruan Tinggi Raharja dapat dilaksanakan dengan menggunakan iPad, smart phone, mobile computing, dan gadget lainnya yang mendukung cara kerja mobile communication dan edutaiment. Pembelajaran iLearning yang mempunyai metode pembelajar, sebagai berikut: Metode pembelajaran yang sudah modern dan maju, serta suatu metode belajar yang interaktif, metode pembelajaran yang memudahkan kita mengerjakan tugas-tugas kuliah, metode pembelajaran yang seru dan tidak membosankan karena disamping belajar kita juga dapat bermain.

Pada dasarnya istilah iLearning (Integrated Learning) berasal dari pemikiran perkembangan Teknologi iPad di Perguruan Tinggi Raharja, yaitu Belajar, Bermain, Berdoa dan Bekerja. Dilengkapi oleh fasilitas Tekhnologi canggih berupa iPad yang didalamnya kita bisa belajar sambil bermain. Biasanya dosen iLearning selalu memberikan tugas dan materinya juga menggunakan fasilitas iPad.

Dalam buku berjudul “iLearning an Effective Learning Method for Higher Education”, Untung Rahardja (2011) menjelaskan bahwa iLearning adalah sistem pembelajaran modern dan terbaru dalam dunia pendidikan yang berbasis 4B yaitu belajar, bermain, bekerja, dan berdoa. Apabila diimplementasikan sebagai arsitektur 4B iLearning, tampak seperti pada gambar satu berikut ini.

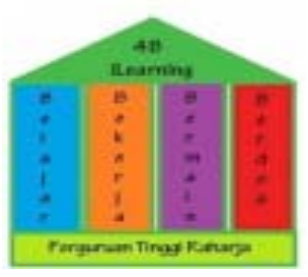

\section{Gambar 1.Gambar Infrastruktur 4B iLearning}

Alasan mengapa semua kegiatan kampus menerapkan sistem iLearning, karena pembelajaran yang secara efisien, praktis dan menyenangkan seperti itu membuat mahasiswa menjadi lebih atractive dan semangat dalam belajar dengan didukung teknologi yang mempermudah jangkauan mahasiswa dalam melakukan interaksi di dalam proses belajar mengajar. Serta metode pembelajaran iLearning yang cara 
pembelajaran dapat membuat mahasiswa dan Dosen merasa nyaman dalam proses belajar mengajar.

Dengan adanya metode pembelajaran iLearning ini, tidak ada lagi metode pembelajaran yang membosankan. Seperti dosen mencatat materi pada whiteboard dan mahasiswa menyalinnya dan menggunakan kertas dalam pembelajaran. Hal yang seperti itu sungguh membosankan dalam proses belajar mengajar di jaman yang modern saat ini.Maka dari itulah sistem pembelajaran iLearning diterapkan di Perguruan Tinggi Raharja.

Perguruan Tinggi Raharja sebagai salah satu lembaga pendidikan unggulan yang berada di Kota Tangerang, berusaha menjawab permasalahan yang ada. Dengan suksesnya sistem yang telah diciptakan menggunakan iLearning sebelumnya, Perguruan Tinggi Raharja menciptakan kembali terobosan baru, yaitu dengan membuat sistem ujian saringan masuk secara online yang dapat memudahkan kegiatan Marketing dengan mengutamakan pelayanan terhadap calon mahasiswa baru dengan membuat sistem iRangers ini pelayanan yang diberikan secara online yang dapat memenuhi kebutuhan mengenai ujian penerimaan mahasiswa baru, yang dimana sistem pelayanan tersebut dapat dilakukan secara insite dan offsite. Dengan adanya sistem ini diharapkan nantinya bagi para calon mahasiswa baru tidak lagi kesulitan dalam mengerjakan ujian dikarenakan alasan yang letaknya di luar kota / daerah.

Dari uraian tersebut menunjukan bahwa kehadiran media iRangers telah mempengaruhi seluruh aspek kebutuhan, termasuk dalam sistem pelayanan kita. Salah satu faktor yang ada diluar individu adalah tersedianya media pelayanan yang memberi kemudahan bagi presenter dari bagian marketing dalam melayani ujian, sehingga menghasilkan sistem pelayanan yang lebih baik.

Sebuah metode pelayanan sangat menentukan hasil atau output yang terciptda dari metode pelayanan tersebut. Sumber daya manusia yang semakin hari dituntut untuk lebih kreatif dan maju. Begitu pula dengan Perguruan Tinggi Raharja, setiap waktu berusaha untuk meningkatkan kualitas dan kuantitas pelayanan yang ada. Tentu saja semua itu dibutuhkan fasilitas yang memadai, oleh karena itu terciptalah sebuah metode pelayanan untuk ujian saringan masuk online yang bernama iRangers.

\section{LANDASAN TEORI}

\section{Pengertian Internet}


Menurut eWolf Community (2012), "Internet merupakan singkatan dari Interconnection Networking, yaitu jaringan komputer dalam skala dunia. Internet terdiri dari banyak jaringan komputer lokal yang saling terhubung sehingga membentuk jaringan global dengan segala macam aturan (protokol). Protokol utama yang digunakan saat ini adalah TCP/IP (Transmission Control Protocol/Internet Protocol), yaitu sekumpulan aturan untuk komunikasi data antar komputer dalam suatu jaringan”.Dalam pengertian lain internet adalah komputer yang terhubung melalui jaringan dan saling berkomunikasi dengan waktu dan wilayah yang tak terbatas.

\section{Pengertian Ujian.}

Ujian merupakan salah satu cara untuk mengevaluasi proses belajar. Dalam dunia pendidikan ujian dimaksudkan untuk mengukur taraf pencapaian suatu tujuan pengajaran oleh siswa atau mahasiswa dapa mengetahui kemampuannya dalam memahami bidang studi yang sedang ditempuh. Bila ternyata hasilnya belum maksimal, maka proses belajar harus ditingkatkan baik kualitas maupun kuantitas. (clara 2006)

\section{Pengertian Online.}

Secara umum, sesuatu dikatakan online adalah bila ia terkoneksi/terhubung dalam suatu jaringan ataupun sistem yang lebih besar. Beberapa arti kata online lainnya yang lebih spesifik yaitu:

1 Dalam percakapan umum, jaringan/network yang lebih besar dalam konteks ini biasanya lebih mengarah pada internet, sehingga 'online‘ lebih pada menjelaskan status bahwa ia dapat diakses melalui internet.

2. Secara lebih spesifik dalam sebuah sistem yang terkait pada ukuran dalam satu aktivitas tertentu, sebuah elemen dari sistem tersebut dikatakan online jika elemen tersebut beroperasional. Sebagai contoh, Sebuah instalasi pembangkit listrik dikatakan online jika ia dapat menyediakan listrik pada jaringan elektrik.

3. Dalam telekomunikasi, Istilah online memiliki arti lain yang lebih spesifik. Suatu alat diasosiasikan dalam sebuah sistem yang lebih besar dikatakan online bila berada dalam kontrol langsung dari sistem tersebut. Dalam arti jika ia tersedia saat akan digunakan oleh sistem (on-demand), tanpa membutuhkan intervensi manusia, namun tidak bisa beroperasi secara mandiri di luar dari sistem tersebut. 
Dengan Internet kita dapat menerima dan mengakses informasi dalam berbagai format dari seluruh penjuru dunia. Kehadiran internet juga dapat memberikan kemudahan dalam dunia pendidikan, hal ini terlihat dengan begitu banyaknya situs web yang menyediakan media pembelajaran yang semakin interaktif serta mudah untuk dipelajari.

\section{Pengertian Open Source}

Kata “open source” pertama kali muncul pada sebuah rapat di Palo Alto California. Ketika itu, Netscape yang merupakan pengembang browser Navigator ingin melepaskan kode sumber dari produk dengan nama Mozilla di bulan Januari 1998.

Merekan ingin membedakan diri dan menghindari konfrontasi ideologis maupun konotatif dengan istilah Free Software yang dipelopori oleh Richard Stallman.Istilah Open Source lazim diterapkan pada kode sumber (source code) dari software yang dibuat untuk kepentingan public secara umum dengan tidak adanya batasan hak atas kekayaan intelektual. Prinsip ini menyediakan kebebasan kepada user untuk membuat isi sebuah software secara bertahap maupun berkolaborasi.

\section{Pengertian Ruby.}

Bahasa pemrograman open source dinamis, mudah dimengerti dan produktif. Sintaks Ruby elegan, natural, mudah dibaca dan ditulis. Ruby adalahbahasa skripting yang berorientasi obyek. Tujuan dari ruby adalah menggabungkan kelebihan dari semua bahasa-bahasa pemrograman scripting yang ada di dunia. Ruby ditulis dengan bahasa pemrogramanC dengan kemampuan dasar sepertiPerl danPython.

Ruby pertama kali diciptakan oleh programmer asal jepang yang bernama Yukhiro Matsumoto. Penulisan ruby dimulai pada February 1993 dan pada Desember 1994 dirilis versi alpha dari ruby. Yukhiro menulis ruby sendiri sampai pada tahun 1996 sudah terbentuk komunitas Ruby yang banyak mengontribusikan perkembangan Ruby.

Saat ini Ruby telah berkembang tidak hanya di Jepang, tetapi diseluruh dunia. Bulan Agustus tahun 2006, Macintosh telah melakukan kerja sama dengan mengintegrasikan Ruby on Rails pada Mac OS X v10.5 Leopard telah diluncurkan bulan Oktober 2007. 


\section{PERMASALAHAN}

Setiap penelitian dimulai dari rumusan masalah yang dilanjutkan dengan pemecahan masalah. Rumusan masalah ini dikategorikan sebagai pertanyaan utama yang dicari dan yang akan dijawab melalui penelitian. Rumusan masalah itu muncul karena adanya gap (kesenjangan) antara (real life condition) kondisi realitas atau nyata dengan (future expected condition) kondisi yang nantinya diharapkan.

Uraian rumusan masalah ini harus didukung dengan teori, survey, dan juga data yang relevan. Adanya rumusan masalah merupakan salah satu faktor penting yang menentukan jalannya penelitian. Suatu masalah perlu diteliti untuk menguraikan masalah - masalah yang ada, untuk menggambarkan atau mendeskripsikan masalah tersebut, dan untuk menemukan solusi atas masalah tersebut.

Masalah adalah kesenjangan (discrepancy) antara apa yang seharusnya (harapan) dengan apa yang ada dalam kenyataan sekarang. Kesenjangan tersebut dapat mengacu ke ilmu pengetahuan dan teknologi, ekonomi, politik, sosial budaya, pendidikan dan lain sebagainya. Penelitian diharapkan mampu mengantisipasi kesenjangan-kesenjangan tersebut.

Masalah yang perlu dijawab melalui penelitian cukup banyak dan bervariasi misalnya masalah dalam bidang pendidikan saja dapat dikategorikan menjadi beberapa sudut tinjauan yaitu masalah kualitas, pemerataan, relevansi dan efisiensi pendidikan.

Pada saat ini Perguruan Tinggi Raharja memiliki suatu metode pembelajaran yang mutakhir. Perguruan Tinggi Raharja telah membuat terobosan baru dalam metode pembelajaran yaitu iLearning. Yang sangat bermanfaat bagi mahasiswa dan dosen untuk mendapatkan kemudahan dalam pembelajaran.

Namun masih terdapat permasalahan-permasalahan yang dihadapi sebelum mereka menjadi Pribadi Raharja. Maka dalam hal ini dapat dirumuskan beberapa permasalahan yang ada pada perguruan tinggi raharja mengenai pelayanan mahasiswa baru dalam menangani Ujian Saringan Masuk (USM) yang masih secara manual. Permasalahan pertama dapat dikatakan bahwa USM tidak praktis dan fleksibel sehingga Calon Pribadi Raharja harus datang ke kampus untuk melakukan ujian jika calon mahasiswa baru yang berada diluar kota tidak bisa mengerjakan diluar kampus. Permasalahan Kedua adalah Presenter yaitu bagian marketing harus 
mengecek satu persatu lembar LJK(Lembar Jawaban Komputer) yang sangat tidak praktis dan terlalu banyak waktu dalam pengerjaannya. Permasalahan ketiga adalah ujian dilakukan menggunakan lembar LJK yang menggunakan kertas dengan seperti ini akan mengeluarkan banyak biaya untuk mencetak LJK ketika habis. Permasalah keempat adalah calon mahasiswa baru mendapatkan informasi kelulusan yang tidak efektif, cepat dan akurat sehingga hal ini menjadi hambatan untuk mereka melakukan registrasi.Permasalahan Kelima adalah pada saat presenter membutuhkan bukti jawaban calon mahasiswa baru harus mencari satu per satu di formulir masingmasing sehingga membutuhkan waktu yang lama.

Dari permasalahan diatas sudah jelas dijabarkan bahwa pada Perguruan Tinggi Raharja dalam melaksanakan USM belum optimal dan tidak dapat memberikan pelayanan yang memuaskan bagi calon mahasiswa baru. Sehingga dari permasalahan diatas dapat disimpulkan secara detail menurut penjabaran tentang sistem pendukung dalam melaksanakan USM untuk calon mahasiswa baru yang tercantum dalam aplikasi Mind Mapping. Dikarenakan proses pembuatan aplikasi ini tidak mudah, dan membutuhkan proses yang bertahap, sehingga dilakukan proses pembuatan aplikasi yang sebenarnya.

Berikut tampilan perancangan Mind Mapping aplikasi iRangers ( iDu Rangers ).

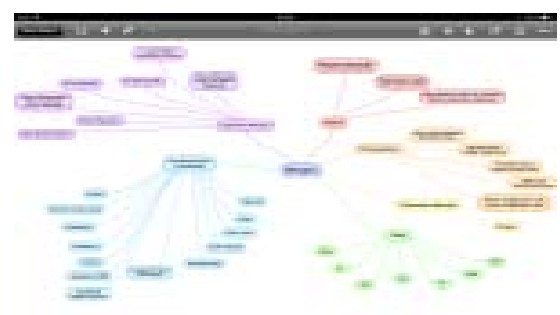

\section{Gambar 2. Mind Maping iRangers}

Tampak pada gambar diatas adalah Mind Mapping penjabaran perihal iRangers ( iDu Rangers ). Maka untuk memenuhi kebutuhan mahasiswa dalam proses pembelajaran iLearning, yaitu bagaimana merancang sebuah sistem pelayanan yang baik dan menarik. nya Sehingga setelah menjadi mahasiswa sudah terbiasa dalam melakukan pembelajaran iLearning yang setiap belajarnya dilakukan secara online, tentunya dengan permasalahan-permasalahan yang terjadi bisa teratasi dengan adanya iRangers ini. 
Sehingga perbaikan mutu pelayanan akan kualitas sistem USM secara online disetiap tahunnya dalam Perguruan Tinggi Raharja akan mengalami peningkatan dan membantu dalam mensukseskan Penerimaan Mahasiswa Baru (PMB).

\section{LITERATURE REVIEW}

Metode leiterarure review dilakukan untuk menunjang metode wawancara dan observasi yang telah dilakukan. Pengumpulan informasi yang dibutuhkan dalam mencari referensi-referensi yang berhubungan dengan penelitian yang dilakukan. Manfaat dari literature Review ini antara lain :mencari referensi-referensi yang berhubungan dengan penelitian yang dilakukan. Manfaat dari literature Review ini antara lain :

1. Mengidentifikasikan kesenjangan (identify gaps) dari penelitian ini.

2. Menghindari membuat ulang (reinventing the wheel) sehingga banyak menghemat waktu dan juga menghindari kesalahan- kesalahan yang pernah dilakukan oleh orang lain.

3. Mengidentifikasikan metode yang pernah dilakukan dan yang relevan terhadap penelitian ini.

4. Meneruskan apa yang penelitian sebelumnya telah dicapai sehingga dengan adanya studi pustaka ini, penelitian yang akan dilakukan dapat membangun di atas landasan (platform) dari pengetahuan atau ide yang sudah ada.

Banyak penelitian yang sebelumnya dilakukan mengenai pembelajaran online. Sebagai salah satu upaya mengembangkan dan menyempurnakan laporan penelitian ini sebagai salah satu dari penerapan metode penelitian yang akan dilakukan. Beberapa literature review tersebut diantaranya adalh sebagai berikut:

Penelitian yang dilakukan oleh Danny Wiliam Wongsodari Bina Nusantara tahun 2008 sebagai bentuk Skripsi dengan judul "Analisa dan Perancangan Piranti Lunak Pembangkit Soal Ujian Secara Online dengan menerapkan AJAX”.

Penelitian yang dilakukan oleh Sukriya dari ITS (Institut Teknologi Sepuluh Nopember)tahun 2009 sebagai bentuk Skripsi dengan judul "Perancangan Dan Pembuatan Perangkat Lunak E-Learning Berbasis .Net Menggunakan Teknologi 
Asp.Net 3.5 Dan Ajax Dengan Partial Rendering Untuk Studi Kasus Scored Online Test”.

Penelitian yang dilakukan oleh Antony Susanto dari STIMIK GI MDP.Aplikasi ujian berbasis web ini mengimplementasikan algoritma Fisher-Yates Shuffle yang berfungsi untuk mengacak soal dan algoritma Levenshtein Distance yang berfungsi untuk membandingkan jawaban pada saat pengoreksian. Pembuatan aplikasi akan menggunakan bahasa pemograman PHP dan MySQL untuk pembuatan database dan metodologi yang digunakan adalah pendekatan prototype.

Penelitian yang dilakukan oleh Aris Puja Widikda,Dkk dari UNS. Evaluasi Pemeriksaan Online Menggunakan Moodle Belajar Sistem Manajemen Pada Pneumatichhydraulic Perkuliahan.

Penelitian yang dilakukan oleh Alvin Assianto Leiman.Dkk.Aplikasi ujian online menggunakan koneksi Internet untuk berkomunikasi dengan server. Aplikasi ujian online dibuat dengan menggunakan bahasa pemrograman Java. Berdasarkan hasil pengujian, aplikasi ini dapat berjalan dengan baik pada smartphone dengan sistem operasi Android versi 4.0 (Ice Cream Sandwich) ke atas dalam orientasi landscape.

Dari hasil literature review yang ada, dapat disimpulkan bahwa sistem ujian online saat ini sudah banyak yang mengembangkan dan ini dapat diterapkan guna menggantikan sistem ujian tradisional di Perguruan Tinggi Raharja.

Dari proses ujina secara manual sampai mengggunakan sistem ujian nonline ini agar memiliki lulusan yang berkualitas. Oleh karena itu, untuk menindak lanjuti penelitian seperti yang dikemukakan diatas, maka dilakukan penelitian berupa "UJIAN ONLINE CALON MAHASISWA BARU BERBASIS ILEARNING EDUCATION MARKETING PADA PERGURUAN TINGGI“.

\section{PEMECAHAN MASALAH}

Untuk mengatasi berbagai masalah diatas, maka diperlukan proses yang cepat dan efisien dalam melaksanakan USM calon mahasiswa baru secara online agar mereka bisa mengerjakan dimana pun tanpa harus datang ke kampus yang berupa sebuah website. terlebih untuk suatu sistem informasi yang efektif dan akurat. Saat kita bermaik dengan jari di iPad kita,saat itulah kita sedang belajar. 
Menjelajah dunia maya dengan mencari kebutuhan informasi yang sangat kaya dan berkualitas tentunya itulah belajar yang sesungguhnya. Bila kita mendefinisikan belajar adalah membaca,menulis,tentunya itulah metode pembelajaran yang kuno.Kita butuh perubahan karena ini dunia teknologi yang sudah begitu maju dan canggih yang akan selalu membutuhkan perkembangan dari berbagai sisi.

Oleh karena itu berdasarkan analisa dari segi kekurangan serta kebutuhan saat ini ,kebutuhan terhadap sistem hendaknya sistem dapat mudah diakses dan user mendapatkan pelayanan secara optimal yang dibutuhkan oleh calon mahasiswa baru di Perguruan Tinggi Raharja sehingga dapat memaksimalkan berbagai bentuk suatu pelayanan kepada calon mahasiswa baru.

Segala hal yang pada dasarnya untuk mengatasi berbagai masalah diatas,maka diperlukan proses yang cepat dan efisien dalam melayani seluruh permintaan pelayanan dukungan yang banyak dan teratur dalam melaksanakan USM calon mahasiswa baru yang berupa suatu media online yang bisa diakses oleh jaringan internet,terlebih untuk suatu sistem informasi yang akurat.Untuk menjelajahi dunia maya dengan mencari dan memperoleh informasi yang sangat relevan dan berkualitas serta memudahkan dalam proses pengambilan keputusan.

Sitem iRangers (iDu Rangers) merupakan media pendukung dalam melaksanakan USM untuk calon mahasiswa baru online yang dapat dikerjakan secara insite maupun offsite,penggunaan sistem iRangers dapat meningkatkan kualitas pelayanan calon mahasiswa baru untuk mendukung suksesnya PMB (Penerimaan Mahasiswa Baru) disetiap tahunnya.

Dalam iRangers ini terdapat berbagai macam feature pendukung,yaitu adanya fasilitas Assigment untuk melakukan Ujian yang terdapat 5 Assigment yaitu USM, Hasil Perminatan, English Section 1, English Section 2, English Section 3, selain itu juga memberikan informasi posting didalam halaman News.

Dan Presenter dalam meliha hasil ujian sudah tersedia menu Gradebook yang hanya tinggal export.Kemudian adanya beberapa Clasess yang dibagi beberapa sesuai periode gelombang dan kebutuhan training iLearning.

Untuk memudahkan penjabaran dari sistem iRangers, akan dilakukan cara alternatif penggambaran sistem melalui alur flowchart.Dibawah ini merupakan alur flowchart program iRangers. 
1. Flowchart Sign Up iRangers

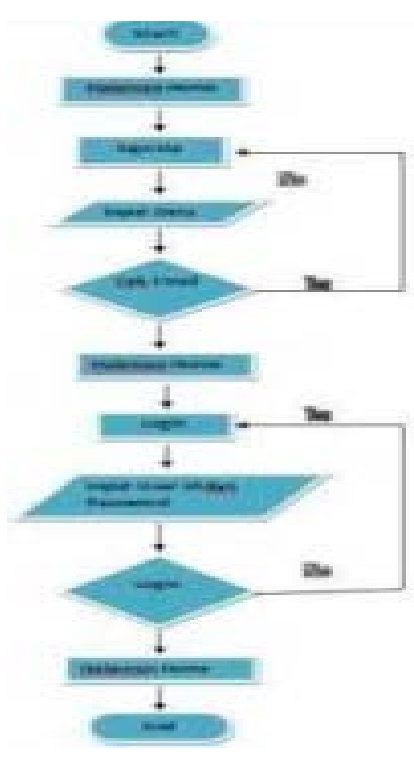

Gambar 3. Flowchart Sign Up iRangers

Pada Flowchart diatas menjelaskan alur sign up atau registrasi untuk menjadi student di class iRangers. Langkah awalnya yaitu dengan mengakses URL www.rangers.edu20.org. CMB akan mengisi form sign up dengan menginput data pribadi.sebagai tindakan pengamanan, iRangers telah memiliki default alamat email berdomain raharja.info untuk menghindari dari spammers.

Jika data yang dimasukan valid, maka status student CMB akan didapatkan. Dengan username dan password yang sudah diinputkan pada saat sign up, CMB dapat login ke dalam iRangers untuk melakukan USM dan Training iLearning atau yang biasa disebut dengan RiJP.

Diagram rancangan sistem iRangers dapat pula dijabarkan melalui Use Case Diagram yang menggambarkan kebutuhkan sistem dari sudut pandang user dan memfokuskan pada proses komputerisasi.Untuk melihat peranan dari komponen yang terlibat didalam sistem iRangers, dapat dilihat pada gambar use case dibawah ini. 


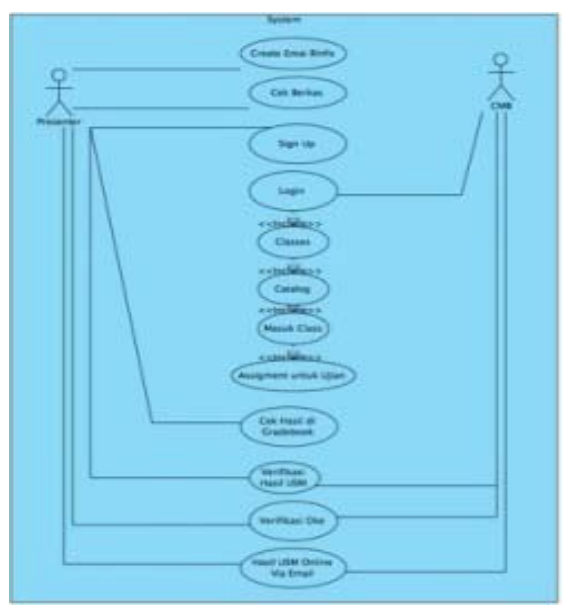

\section{Gambar 4. Usecase Diagaram Alur USM iRangers}

Use case pada dasarnya merupakan gambaran dari proses sistem secara keseluruhan yang melibatkan actor dalam hal penggunaan. Dalam use case diagram USM ini terdapat 2 actor yang terlibat pada sistem iRangers, dimana masing-masing actor memiliki hak akses yang berbeda.

Student (actor 1) melakukan login pada iRangers dengan membuka portal alamat www.rangers.edu20.org.. Setelah member berhasil login, akan terarah pada halaman home iRangers. Pada halaman home, student diarahkan untuk ke menu classes.

Setelah memilih menu clasess pilih menu catalog student akan memilih class sesuai dengan periode gelombang, kemudian setelah memilih class student memilih class dan memasukan access code yang sudah dikirimkan melalui email. Sedangkan untuk Teacher (actor 2) hak aksesnya mencakup keseluruhan kebutuhan class yang ada untuk melihat kegiatan dari student dan juga mengrade hasil usm.

Penerapan sistem iRangers ini diharapkan dapat membantu Calon Pribadi Raharja dalam kemudahan melakukan USM dimanapun dan kapanpun dalam kaitannya dengan pembelajaran iLearning dan diharapkan dapat berguna bagi CMB dan juga divisi pemasaran dalam memberikan pelayanan dan informasi yang akurat, cepat dan efektif. 
Di bawah ini merupakan listing program iRangers pada Perguruan Tinggi Raharja, yaitu sebuah script dari proses USM. Berikut listing programnya :

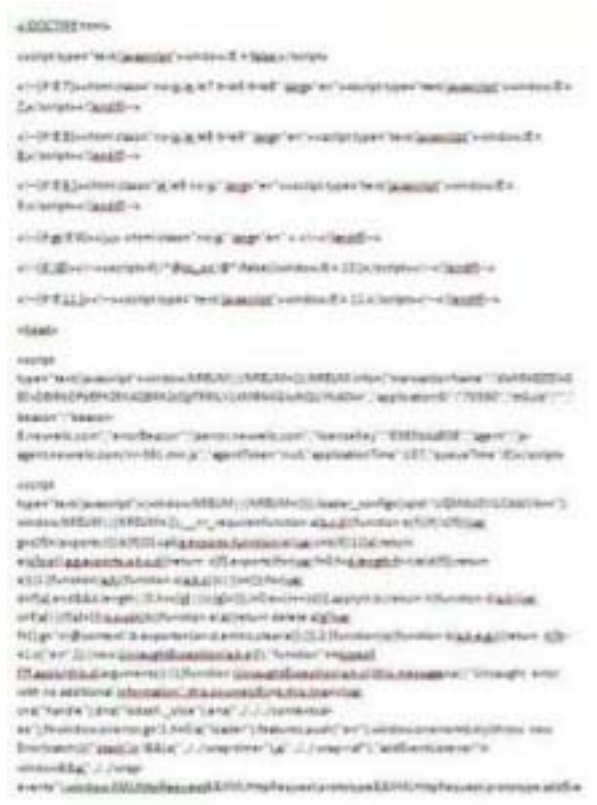

Gambar 5. Listing Program iRangers

\section{IMPLEMENTASI}

Sebagai perwujudan rancangan sistem pada penelitian diatas.maka dibuatkanlah sebuah sistem informasi berbasis web yaitu media USM Online di iRangers.Dan berikut adalah tampilan dari sistem iRangers

\section{Tampilan Logo iRangers}

Gambar dibawah ini adalah tampilan logo iRangers. Dalam logo iRangers terdapat filosofi yang menggambarkan keterkaitan sistem iRangers dengan Perguruan Tinggi Raharja. Setiap bentuk dan warna memiliki makna yang berbeda. 


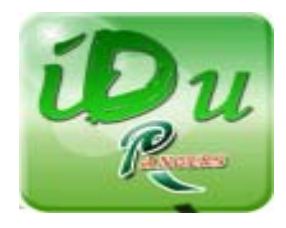

\section{Gambar 6. Logo iRangers}

2. Tampilan Awal Portal iRangers

Menu portal home ini merupakan tampilan yang pertama kali akan muncul saat member membuka website iRangers. Di dalam menu portal home terdapat navigasi yang akan dibutuhkan Calon Mahasiswa Baru untuk melakukan ujian. Salah satunya adalah seperti menu form sign up.Pada menu home juga terdapat menu login dan contact bagi yang belum melakukan sign up.

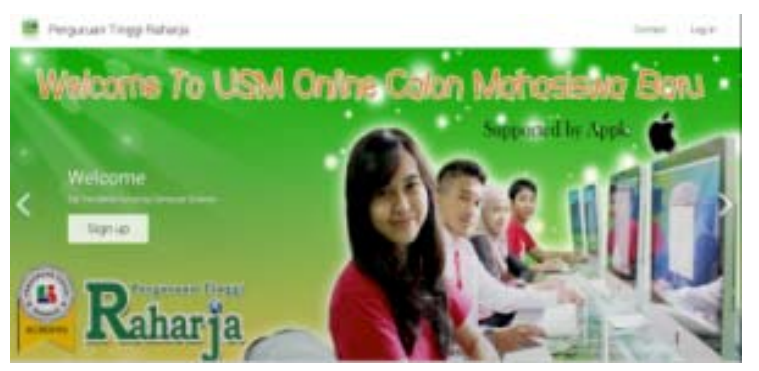

\section{Gambar 7. Tampilan Awal Portal iRangers}

Seluruh CMB yang sudah join dalam iRangers dapat membuka website iRangers melalui browser dengan URL www.rangers.edu20.org.

\section{Tampilan Menu Sign Up iRangers.}

Form Sign Up berisi kolon pengisian data berupa nama awal, nama belakang,password,confirm password,user id, tahun lulus, bulan tanggal tahun lahir, student id dan email CMB. Data yang diinput harus valid agar dapat diproses menjadi student di iRangers.Hal ini menghindari adanya spammers yang mendaftar dan tidak masuk kedalam email CMB.Maka sistem diatur untuk memiliki default email berdomain raharja.info 


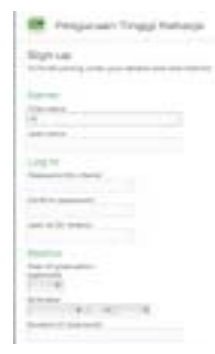

\section{Gambar 8. Halaman Menu Sign Up}

4. Tampilan Menu Login iRangers.

Tampilan Login ini berisikan dari user id dan password yang sudah dibuat melalui sign up. Dan CMB juga akan mendapatkan Notification Login Information melalui email raharja.info yang sudah diberikan oleh Presenter.

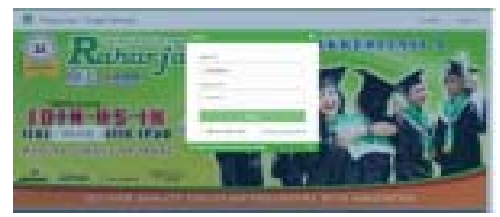

\section{Gambar 9. Tampilan Menu Login iRangers}

5. Tampilan Halaman Home iRangers.

Pada halaman home ini berisikan dari berita, dan assigment to grade agar teacher mengetahui mana yang akan dinilai.dan halaman ini juga CMB bisa melakukan posting dan comment di news.

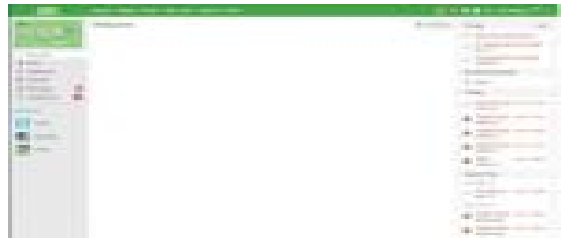

Gambar 10. Home iRangers 
6. Tampilan Menu Classes.

Menu classes ini memperlihatkan class yang terdapat di iRangers. Dalam class ini masing-masing memiliki kebutuhan sendiri dan ada batasan waktu dan masa penggunaan.Mulai dari tanggal bulan tahun keaktifannya.

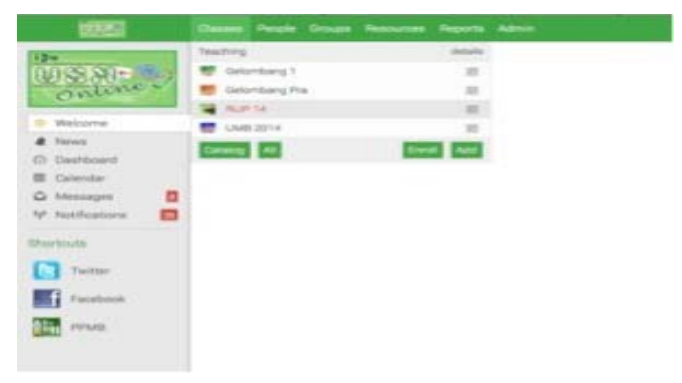

Gambar 11. Tampilan Menu Classes

6. Tampilan isi Menu Home Classes.

Tampilan menu classes ini terdapat menu-menu yang dibutuhkan oleh Presenter dan CMB

Seperti ada news,lessons,calender,assigments,gradebook,people,attendance yang tidak semaua bisa diakses oleh CMB. CMB hanya bisa mengakses assigments, forum,news,people,dan calender.

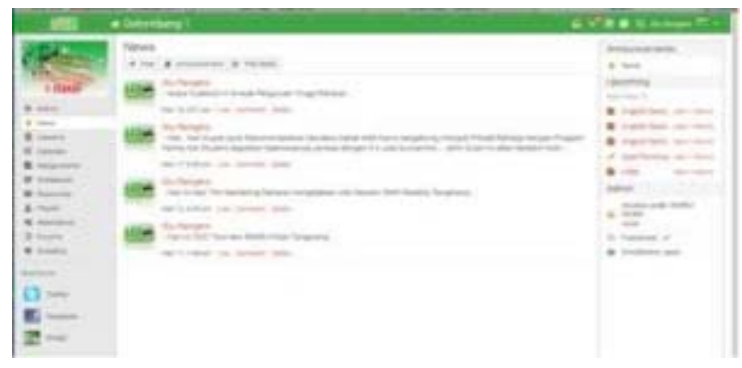

Gambar 12. Tampilan Isi Menu Classes iRangers 
7. Tampilan Menu Assigment.

Tampilan Menu Assigments ini terdapat 5 Assigments yang harus dikerjakan oleh CMB. dan masing-masing mempunyai timing. Assigment ini terdiri dari Hasil Perminatan, USM, English Section 1, English Section 2, English Section 3.

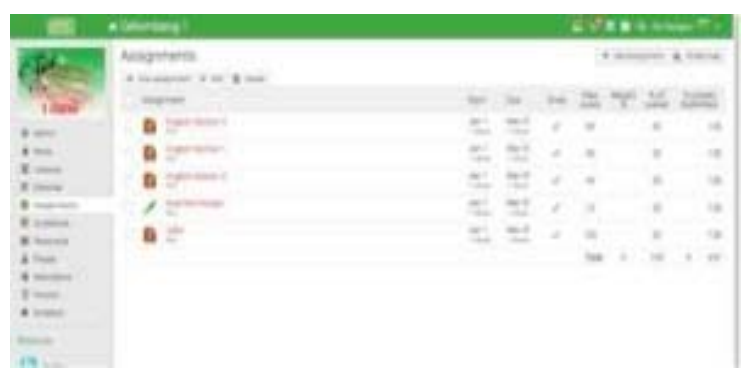

Gambar 13. Tampilan Menu Assigments.

8. Tampilan Gradebook iRangers.

Gradebook ini menampilkan hasil ujian yang sudah diselesaikan oleh CMB. Dalam Gradebook ini nilai sudah otomatis mengoreksi hasil ujian yang bernilai benar. Dan masing-masing memiliki kategori assigments.Dan gradebook ini bisa juga di export kedalam excel yang berbentuk format csv atau xls. Yang memudahkan Presenter untuk mengetahui hasil dan menginput nilai kedalam integram.

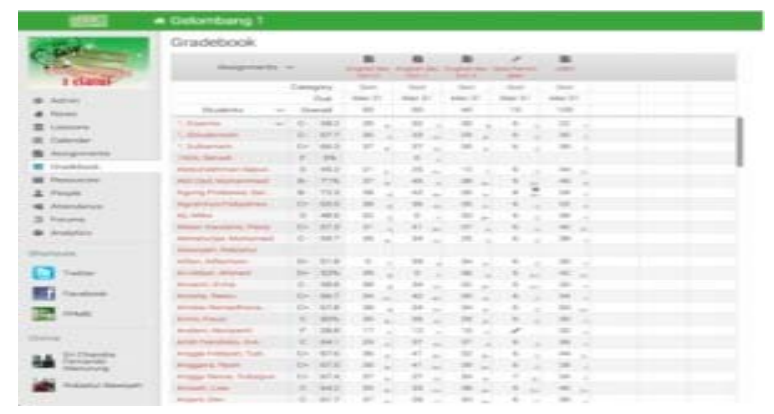

Gambar 14. Tampilan Gradebook iRangers. 


\section{KESIMPULAN}

Sistem Informasi berbasis media web memiliki peranan yang penting dalam terwujudnya konsep 4B iLearning,untuk itu diperlukan sebuah media dalam melakukan Ujian Saringan Masuk(USM).

Lembar Jawaban Komputer ( LJK ) merupakan media USM yang sebelumnya dijalankan oleh bagian marketing pada saat CMB akan melaksanakan USM di Perguruan Tinggi Raharja. Namun masih dikatakan bahwa sistem tersebut belum sangat optimal dikarenakan belum terpenuhinya seluruh kebutuhan dalam melaksanakan USM.

iRangers (iDu Rangers) merupakan satu solusi sebagai media untuk melaksanakan USM dan Training secara online karena iRangers dapat diakses secara fleksibel hanya dengan adanya koneksi internet menggunakan device Android,Blackberry dan iPad menjadikan seluruh calon mahasiswa baru dapat melakukan USM Online dengan mudah dan efisien.

Dengan menerapkan iRangers terdapat beberapa keunggulan yaitu sistem bersifat online dan terpusat, proses untuk melakukan USM bisa secara insite maupun offsite, presenter tidak perlu lagi mengoreksi satu persatu dari hasil USM,nilai USM otomatis akan masuk dalam gradebook. Selain itu memudahkan CMB untuk mengikuti USM jika berada di luar daerah maupun kota

\section{DAFTAR PUSTAKA}

[1] Astuti,Erni. 2014.Definisi Online.Tangerang:Perguruan Tinggi Raharja

[2] Anzani,Farid.2010?Analisis Dan Perancangan Sistem Ujian Online Penerimaan Siswa Baru Berbasis Intranet Pada Madrasah Aliyah Negeri (MAN) REO Kabupaten Manggarai”.Naskah Publikasi.NTT:STMIK AMIKOM Yogyakarta.

[3] Clara.2006.Pengertian Ujian.diambil dari http://repository.upi.edu/1343/2/ s_d5451_0706537_chapter1.pdf 
[4] Community,eWolf. 2012.Internet merupakan singkatan dari Interconnection Networking diambil dari http://repository.upi.edu/1343/2/ s_d5451_0706537_chapter1.pdf

[5] Dewi Arriesanti,Hani,Muhamad Yusup,Ceria Marcelina.2014.”Penerapan Multimedia Audio Galery iLearning Community and Services (MAGICS) Sebagai Media Penyimpanan Dokumentasi Pada Perguruan Tinggi Raharja”.CCIT Journal ISSN:1978-82882.Tangerang:Perguruan Tinggi Raharja.

[6] Leiman,Alvin.Assianto,Andreas Handojo, Agustinus Noertjahyana.2013?Aplikasi Ujian Online Pada Mobile Device Android”.Jurnal Infra. Yogyakarta:Vol 1 No.3

[7] Rahardja,Untung.2011?iLearning an Effective Learning Method for Higher Education”:Perguruan Tinggi Raharja

[8] Rahardja,Untung,Meta Amalya Dewi,Citra Destianty.2014.”Kinerja Role Online System Ticketing Raharja (ROOSTER) Dalam Menunjang Sistem Pelayanan iDuHelp! Pada Perguruan Tinggi Raharja.

[9] Sukriya.Perancangan Dan Pembuatan Perangkat Lunak E-Learning Berbasis .Net Menggunakan Teknologi Asp.Net 3.5 Dan Ajax Dengan Partial Rendering Untuk Studi Kasus Scored Online Test.ITS:Indonesia,2009.

[10] Susanto,Antony,Henky Honggo.2012.’Perancangan Ujian Online pada STMIK GI MDP Berbasis Web”.STIMIK GI MDP.Palembang:Jurnal.

[11] Wongso,Danny Wiliam.Analisa dan Perancangan Piranti Lunak Pembangkit Soal Ujian Secara Online dengan menerapkan AJAX.Bina Nusantara:Indonesia,2008. 
